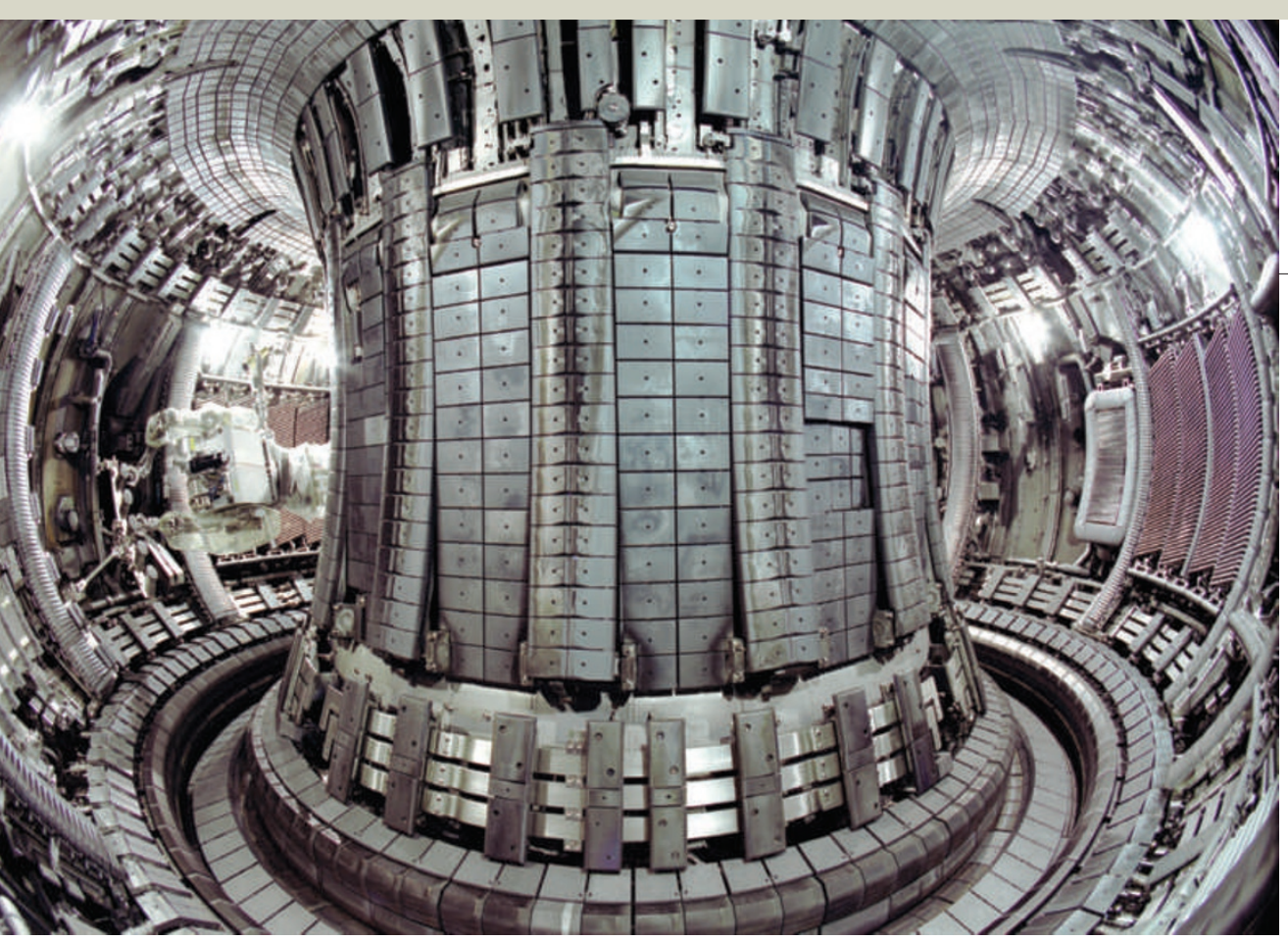

Fusion force: inside the tokamak used to confine plasma at the Joint European Torus, Culham, UK.

亗 from Europe, Japan, Russia and the United States. Its dimensions were defined by scaling laws derived from data collected worldwide. In 2004 and 2005, these four partners were joined by China, South Korea and India. Soon after, the seven partners agreed to construct ITER at Cadarache in the south of France. The ITER international organization, which was established by treaty in 2006, is a collaboration of unprecedented scale. Its seven partners represent more than half of the world's population. The annual budget for ITER construction is about $€ 0.5$ billion (US $\$ 0.7$ billion). This may seem high, but it is a tiny investment compared with the annual worldwide cost of electricity, which stands at around $€ 2$ trillion based on the average cost per kilowatt hour in 2007 in the European Union.

The fiftieth anniversary of international fusion research was marked in October 2008 with many lectures on the history of fusion (see http://fire.pppl.gov), which showed that fusion scientists have not lived quiet lives during this time. Teller and Artsimovich were right — the physics and technology of fusion are challenging, but the fusion community can be proud of its progress.

Yet this community will not recognize its own history in Seife's book. As admitted in the title, it is a rather strange history. After relating at length the early years of fusion research, it concentrates disproportionately on two table-top fusion fiascos - cold fusion and bubble fusion - generated by isolated individuals.

The book leads without proof to the dubious conclusion that "Over and over again, desperate scientists have deceived themselves and their peers - and cheated - in hopes to keep their fusion quest alive". Yet it focuses on outsiders to the field, who thought they had made a major discovery and who, after having been proven wrong when their results could not be repeated by others, did not have the courage to admit their errors. Thankfully, the book does not identify any scandal within magnetic fusion research, the main line for fusion energy. But as a result, it pays too little attention to this large international community. Whereas the dream of limitless energy may afflict isolated scientists, it is certainly not applicable to all

\section{Obsession: A History \\ by Lennard J. Davis \\ University of Chicago Press: 2008. 296 pp $\$ 27.50, £ 16$}

A battle for the public good has been waged for centuries between qualified doctors of medicine with formal training and their 'quack' counterparts. As scientific analysis has come to be accepted, we have demanded more evidence from our physicians. Despite a lingering love-affair with alternative medicines such as homeopathy, patient-consumers today expect more than snake oil and bedside charm. Into this market lands Lennard Davis's latest book, Obsession.

The stereotypical view of a scientist, which rings true of many, is of an obsessive individual working long hours, worrying about minutiae and trying to replicate experiments against an approaching deadline. Davis looks at this form of obsession and others. He discusses the mania of novel writing in the nineteenth century, when prolific authors such as Émile Zola fusion researchers as the author suggests.

The book identifies correctly that peer review is a necessary prerequisite for preventing fiascos. Scientists who call on journalists to make announcements without having had the traditional discussions with colleagues followed by publication in a peer-reviewed journal are in danger of damaging their reputation. Yet peer review may not always be sufficient. In addition to internal reviewing, in the late 1980s JET set up an internal database on which its experimental data were made available. Researchers within the organization can easily cross-check a scientific claim made by their colleagues. An open, international, multidevice database followed in the early 1990s, which has proven to be a sound basis for progress in fusion research. Such a system protects scientists from the insidious distortion of reality that can be provoked when they remain too isolated. Maybe Seife himself is a victim of 'wishful thinking' and should have sought peer review before publishing such a strange thesis.

Jean Jacquinot is scientific adviser to the French High Commissioner for Atomic Energy at the Commissariat a l'Energie Atomique (CEA), 91191 Gif-sur-Yvette, France, and the former director of both JET and the CEA magnetic fusion research group.

e-mail: jean.jacquinot@cea.fr

\title{
Our culture of obsession
}

would write for days and nights at a time. The obsessive Zola became a subject of obsessive study by his contemporaries, and Davis guides us through the sociocultural evolution of the disease now known as obsessive-compulsive disorder. There are fascinating examples throughout the book, not least in his discussion of obsessive love and sex.

Davis tries to untangle the central question of what constitutes obsession. If I check my car doors are locked a couple of times before I leave it parked each morning, am I being obsessive? What about washing my hands repeatedly? Where is the line between obsession as a harmless fact of life, and when it becomes a mental illness? It is far from normal to wash one's hands so often one develops skin diseases, or to be unable to leave the house because of fears one has left the doors unlocked.

Obsession provides an insightful and nuanced review of the history of this tragic illness by exposing obsessive behaviour and contrasting it with the common, mildly obsessive behaviours we all engage in. The question of difference, and thus definition, is a recurring 
motif. Davis is a professor at the University of Illinois in the departments of English, Medical Education, and Disability and Human Development, and has an interesting broad perspective. He insists that to treat an illness effectively, we must understand its history and evolution in a cultural context. Obsession has evolved from being subjacent to demonic possession into something to be almost proud of, to want even. Obsession is the hallmark of genius, of industry and perhaps of modern life, such as our need to regularly check e-mail.

Davis argues for the provision of a narrative framework to medicine, to understand both the disease entity itself and the illness that results from it. This raises the interesting question of whether we need a new type of clinician to help a patient understand their disease through such a narrative.

Davis also asks us to agree with a reclassification of obsession and thereby most, if not all, mental illness. But it is not clear into what. He asks us to assume that science and medical knowledge are responsible for the creation of obsessive culture because of their reductionist approach that observes too strictly the one gene, one disease schema. By this logic, it follows that scientists and physicians are themselves obsessive and unable to render any judgement. $\mathrm{He}$ addresses them in his introduction: "some clinicians and researchers who have miraculously persisted in reading my introduction up to this point will all the while have been shaking their heads at the ignorant insouciance of my project." Unfortunately, he is right. His elegant approach to reclassifying obsession, and by extension obsessive-compulsive disorders, is clouded by a post-modernist demonization of science.

Many facts and statements in the book are misleading. For example, "We are in the very early days of understanding the neurochemical and electrical activity of the brain," says Davis. But our current understanding of human physiology and disease follows centuries of study and analysis. The diagnoses we render now are based on an infinitely larger body of knowledge than those of our forebears who prescribed a good bleeding when one was feeling melancholic; hardly early days.

Davis gives us a witty and interesting historical tour of a fascinating subject. However, by presenting science as excessively reductionist and as responsible for the mis- or over-diagnosis of obsession, his arguments for reclassifying the disease remain incomplete and lack scientific rigour.

Ian Brooks is a neuroscientist at the Clinical and Translational Science Institute, University of Tennessee Health Science Center, Memphis, Tennessee 38163, USA.

e-mail: ibrooks1@utmem.edu

\section{$Q \& A:$ Chemistry in the kitchen}

\section{Voted the world's best restaurant, Spain's elBulli near Barcelona offers an unusual culinary experience, from hot velvet-crab aspic with mini-corncob couscous to ice-cold liquorice nitro-dragon dessert. Innovative head chef Ferran Adrià explains how science and haute cuisine can work together.}

\section{What will a guest find at elBulli?}

It's not just about the food, it's an experience in itself. Cooking is a language. I'm expressing myself and everyone perceives it in a different way, like a piece of theatre. Each person takes away something new. In most human activities it would be normal to find humour, irony and deception. The one place this isn't expected is in the kitchen.

\section{What are you doing now?}

At the moment my team and I are working with a very strange ingredient, veal cartilage. We're also designing a new version of the Chinese 'thousand-year-old egg' [traditionally an egg preserved in clay, salt, ash, tea and lime]. I spend half the year composing at my workshop in Barcelona, and the other half interpreting in the kitchen at elBulli.

\section{How hard is it to develop new dishes?}

Last year we ran 4,000 tests and only about 300 of them panned out. Everyone learns from their mistakes - it's a necessary consequence of being creative. The important thing is to have lots of ideas simmering. Some of these ideas will work, and from these we build our new dishes.

\section{Do you ever seek advice?}

As with any other art, when my creative team needs something specific we go to an expert such as a scientist or historian. But

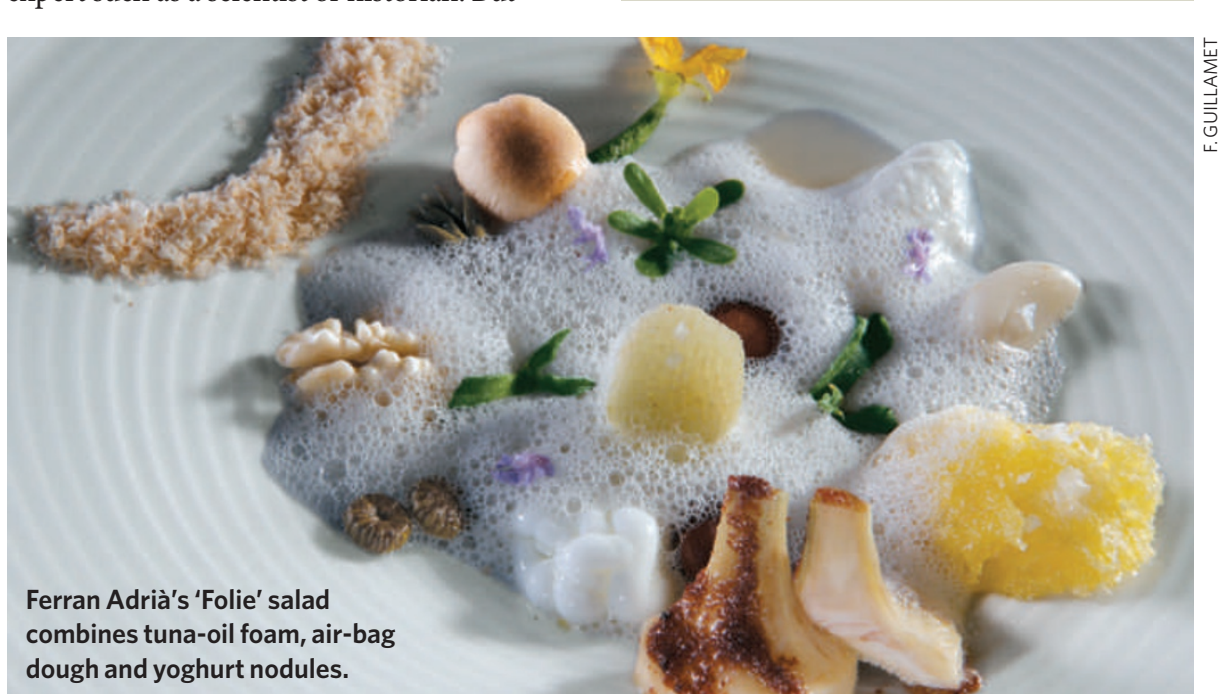

when it comes to everyday ingredients, we don't usually consult researchers. Our work is systematic: you have to be very organized to achieve a sense of anarchism. It's not possible to grasp our work without seeing it for yourself - it would be like trying to describe eating an Amazonian fruit you've never tried.

\section{Where do you find new ingredients?}

I recently went to the Amazon, which has incredible fruits, some of them unknown to science. Under jungle conditions, many fruits ferment naturally. I also studied them in museums, in markets and with biologists.

\section{Has your work raised any scientific questions?}

It is having an influence in the world of science. I visited the physics department at Harvard University last month to talk about this. The dialogue between science and cooking is not new. Bread making has been considered a chemical process for hundreds of years, and the food industry has relied on chemists for almost a century. But only recently has there been a dialogue between science and haute cuisine.

Interview by Jascha Hoffman, a writer based in New York.

\section{A Day At elBulli \\ by Ferran Adrià, Albert Adrià and Juli Soler Phaidon Press: 2008.600 pp. £29.95, €45}

